\title{
Network science and e-tourism
}

\author{
Rodolfo Baggio ${ }^{1,2}$ (D) Matthias Fuchs ${ }^{3}$
}

Received: 17 October 2018 / Accepted: 2 November 2018 / Published online: 12 November 2018 (c) Springer-Verlag GmbH Germany, part of Springer Nature 2018

Almost 20 years ago, the publication of three papers (Barabási and Albert 1999; Faloutsos et al. 1999; Watts and Strogatz 1998) started an incredible strand of interdisciplinary research on the structural and dynamic characteristics of complex networks. Although in some disciplines in the social sciences the idea of analyzing the relationships between different actors had produced some interesting results (Freeman 2004), it is only with the relatively easy availability of large quantities of data provided by the online world that scholars were able to gather statistically significant amounts of elements and unveil a number of patterns and behaviors, almost unexpected up to then.

The idea at the basis of this network science is that any system, no matter how small or large, how simple, complicated or complex, human or artificial, is ultimately made of a number of elements connected by some kind of relationship (Maromodoro and Yates 2016). It is quite difficult, if not impossible, to understand the nature and the behavior of a system if the network behind it is ignored (Amaral and Ottino 2004). Moreover, when different systems show similar network topologies they also show similar behaviors, so that by working by analogy it is possible to improve our capabilities to better understand even highly complex or complicated environments or to conceive new ideas and hypotheses (Bailer-Jones 2002; Bokulich 2015).

The main objective of a network study is to count, map and analyze the patterns of connections between the elements of any system, be it a natural, artificial, social, ecological, or economic, that can be modelled as an ensemble of distinct elements or actors (the nodes or vertices of the network) that are connected by the relationships existing between them (the links or edges), that can also carry a

Rodolfo Baggio

rodolfo.baggio@unibocconi.it

Matthias Fuchs

matthias.fuchs@miun.se

1 Master in Economics and Tourism, Bocconi University, Via Röntgen, 1, 20136 Milan, Italy

2 Tomsk Polytechnic University, 30, Lenin Avenue, Tomsk 634050, Russia

3 Department of Tourism Studies and Geography, The European Tourism Research Institute (ETOUR), Mid-Sweden University, Kunskapens Väg 1, SE-83125 Östersund, Sweden 
weight (cost, importance etc.) or be asymmetric (there is a direction in the connection). The bases for these studies are rooted in the methods of the mathematical graph theory (Diestel 2016), but have had a number of improvements, variations and expansions that have provided a large number of metrics for measuring static and dynamic features, and for producing statistical models for the evolution of the systems considered (Barabási 2016; Bornholdt and Schuster 2003; da Fontoura Costa et al. 2007; Newman 2010).

It is important to remark here that much research has also strengthened the idea that purely qualitative or purely quantitative methods are meaningless when studying a complex system. Despite the many discussions and distinctions, there is not only a complementarity between the two approaches, but a full and reliable understanding of such systems, and the ability to obtain meaningful outcomes, requires (almost mandatorily) a full integration of the two views (Baggio and Del Chiappa 2016; Jørgensen 2016; Kelman et al. 2016). Although the network metaphor might show some fuzziness, this disappears when hard data are added, thus providing theoretically rigorous, complete and elegant analysis (Wellman 2002).

Even from a purely quantitative point of view, no single metric (or limited set) provides a clear idea of the characteristics associated with a complex network. The properties of a complex system are distributed, and may change over a range of scales and times, and our assessments depend on the level of detail used in describing them. An analysis conducted at a single level of details could turn out incomplete, and the outcomes could be dependent on the selected granularity (Marchiori and Possamai 2015). Therefore, a rigorous network-study should include three levels of investigation: a macroscopic level, in which the global topological (structural) characteristics of the network are examined, a mesoscopic level in which possible intermediate structures (communities, hierarchies etc.) of the network are explored, and a microscopic level in which the properties of the single elements (nodes), and their immediate neighborhoods are inspected.

Since the very beginning, tourism research has made clear that the phenomenon is a complex one, that involves many and various actors, groups, activities, relations, so that the use of network science would seem a natural undertaking. Despite that, it is only relatively recently that network analysis methods have been applied to the study of some tourism related activities or systems. However, after a slow and difficult start, network science has established itself as a useful and powerful approach for the whole domain. The recent reviews on this theme are a good witness of this increasing interest (Baggio 2017; Casanueva et al. 2016; van der Zee and Vanneste 2015).

The application of network science in the tourism domain is still at a relatively early stage of development, but from the growing number of works it appears clearly that the methods are able to provide interesting and useful outcomes for both theory and practice. They may make available better weapons to deepen the level of understanding and set up more efficient and effective tools for governing organizations and destinations (Aubke 2014, p. 18): "After all, a network approach not only allows one to understand the problem management is facing, but also to understand the system that causes the problem." 
For the future, we hope to see sophisticated studies, mainly considering the multidimensional nature of tourism systems, their dynamic properties of networks and of the processes based on a network or combinations of networks. Most importantly, in the e-tourism context, we expect studies that are making use of the increasing amount of network data generated and stored electronically in the various e-tourism ecosystems (Mariani et al. 2018). Models and simulations, whether purely analytical or agent-based (Amelung et al. 2016; Johnson et al. 2017), can prove quite useful in this respect for building scenarios, projecting changes, amendments or assessments to tourism systems and components, and allow more efficient actions.

In this special issue on Network Science in e-Tourism, we are collecting a number of contributions that use network analytic methods to examine the tourism online world. More precisely, three full papers and one research note passed the double-blind review process. Thus, beside the authors of the papers, we thank also the reviewers of the Journal of Information Technology \& Tourism for their excellent review service and valuable comments to further improve the manuscripts.

The research paper by Ladan Ghahramani (North Carolina State University), Jalayer Khalizadeh (University of Central Florida) and Birenda KC (University of North Texas) explores tour guides' communication ecosystems among members of the world largest professional tour guides organization, the World Federation of Tourist Guide Association (WFTGA). This organization is serving over 78 member associations and 200,000 individual tour guides from more than 70 countries being a valuable source for tour guides' professional development, as it provides access to information about qualified members, training, conferences and licensing worldwide. The authors define a communicative ecology as 'the context in which communication processes occur'. Three layers of interpretation of communicative ecologies are proposed: First, the technological layer refers to communication media and technologies involved, including modern (e.g. social media), and traditional media. Second, the discursive layer refers to themes and content of the (digital or analog) communication. Finally, the types of actors and their network compose the social layer. By using data collected at the 17th WFTGA convention in Tehran, Iran, five types of tour guides' communication ecosystems, such as in-person, social networks, an e-mail, are compared to tour guides' network of colleagues. More precisely, by using exponential random graph modelling (EGRM), seven networks have been modeled to assess homophily and heterophily effects 'controlled' by demographics, such as age, gender and the participation history in previous WFTGA conventions. Interestingly, the explorative study revealed that female tour guides and those who attended previous WFTGA conventions are more likely to develop relationships with network members in all ecosystems, while tour guides with a master's degree develop stronger relationships through social media-based networks. Nevertheless, the likelihood of adding a shared dyad between any two vertices is less then what happened by chance. Thus, the authors conclude that there is room for improving the information flow in all ecosystems of the WFTGA. Finally, the authors argue that diversity (heterophily) is the key driving force in building sustainable and effective communication networks among tour guides on a global scale.

The research paper by Tatiana David Negre, Arminda Alemdida Santana, Juan Hernández and Sergio Moreno Gil (all affiliated with University of Las Palmas de 
Gran Canaria) analyzes the network of digital tourism platforms used by European tourists to search for information when making travel decisions. The increasingly complex network providing information to tourists and connecting tourists is composed by a wide range of interacting platforms, such as review channels, social media platforms, search engines, online travel agencies, communication exchange channels, comparison sites, tour operator's platforms, blogs and microblogs, as well as the various major tourism service providers, like airlines and accommodation suppliers. In order to enhance cross-channel integration by tourism and destination managers, described also as Omni-channel strategy, the study focusses on 178 platforms used by over 13,000 tourists in 19 European countries. More precisely, links between platforms are defined by visitors' use of these sites when searching for information to book their holidays, i.e. not by the 'formal' interrelationships among suppliers, like in previous contributions. In order to gain data on platform usage, a representative online survey was conducted in 19 major European countries: a tourist is connected to a platform if he or she has used the platform to acquire information before visiting a destination-two platforms are connected if the same tourist has used them. To analyze the network, centrality metrics (node degree, betweenness, closeness and eigenvector centrality) and ego-networks are considered. Findings reveal, as to be expected, that Google, Facebook, TripAdvisor and Booking are positioned as the key platforms in the European e-tourism ecosystem, while the next platforms leading in numbers of connections are Trivago, Ryanair, Ving and Neckermann, respectively. Interestingly, however, ego-network analysis of the 'top four' key platforms revealed that connective patterns are differing mainly in the periphery of the networks. In a similar vein of analysis, very particular usage patterns emerge for local platforms in different European countries. While the center of the European e-tourism network is dominated by the 'big four', it can be concluded, that platforms located in the network periphery show enormous potentials to incorporate regional peculiarities thereby empowering destinations and tourism providers to reach and serve their potential visitors through effective Omni-channel strategies.

The aim of the research paper by Egbert Van der Zee (Utrecht University) and Dario Bertocchi (Cá Foscary University of Venice) is to expand the network approach and social network analysis for exploring how UGC can be analyzed and translated into feasible recommendations for destination managers and planners, thus, strengthening data-driven decision-making. By combining reviewed objects with the typically shared reviewers' IDs, the authors identify relational patterns (e.g., profile 'A' generated content on museum ' $\mathrm{X}$ ', hotel ' $Y$ ', and restaurant ' $Z$ ' within the same destination). When combining a sufficiently large number of profiles, the relational space of a tourism destination and the geographic spread of tourism activities are made-up. Furthermore, the topology of the destination network from the eyes of the reviewers is assessable in terms of stability and ease of information flow. The authors study intra-destination review patterns by using ca. 21,000 TripAdvisor reviews on attractions, museums, hotels, restaurants, etc. for the Belgian destination of Antwerp. Findings reveal the typical power-law degree distribution, showing a (core) cluster, limited in number of nodes and having a very high degree (i.e. the main museum, the Cathedral, the Grote Market), a larger ring of connected nodes with a moderate to relatively high degree, and a peripheral cluster with the 
majority of nodes that are only sparsely connected. Interestingly enough, although comparable network densities appear for different reviewer groups, a number of differences are found in the structure and geography of the networks. While for local and Belgian reviewers, a number of museums, heritage attractions and the zoo form the core of the most occurring visitation arrangements, the Grote Market, and the adjacent Cathedral are the main hubs for non-European reviewers. Moreover, a geographic mapping of the reviewed places according to their degrees revealed that geographically less proximate restaurants receive high degrees for local and Belgian reviewers, while for Non-European reviewers, geographical distance seems to be equivalent to relational distance. This core-periphery structure clearly highlights difficulties and challenges for destination management and planning in spreading tourists over spaces in historic cities.

The research note by Fanni Zoé Éber (Mid-Sweden University), Rodolfo Baggio (Bocconi University, National Research Tomsk Polytechnic University) and Matthias Fuchs (Mid-Sweden University) is demonstrating a hyperlink-based network analysis of a multi destination region in South Sweden. While Halland County comprises six municipalities, network data consider websites belonging to 535 tourismrelated organizations and businesses as the elements (nodes) of the regional tourism network showing a totality of 406 hyperlinks (edges). At the macro level, the network turned out to be extremely sparse (e.g. low network density, low global efficiency and small clustering coefficient, negative assortativity), 52\% isolated nodes and only $1.5 \%$ strongly connected elements. Interestingly enough, as network clusters fully reflect the six communities, a multi-destination network did not empirically emerge at the mesoscopic level. In line with Butler's tourism area lifecycle framework, this situation is interpreted by the authors as a natural consequence of an early stage of a destination's development that has not yet built a solid network structure among tourism stakeholders. Finally, on the microscopic level, the authors highlight the most influential (prominent) actors in the multi-destination network by using an 'importance index' defined as the geometric mean of (normalized) centrality metrics, such as degree, eigenvector, clustering coefficient, betweenness and closeness. Interestingly, organizations involved in cultural and sporting activities are clearly dominating the ranking. This is a promising finding for the future prosperity of this destination region, as these particular tourism and leisure activities are strongly bound to the features of this Swedish region, thus, being of high relevance for developing and strengthening an authentic destination brand.

\section{References}

Amaral LAN, Ottino JM (2004) Complex networks - augmenting the framework for the study of complex systems. Eur Phys J B 38:147-162

Amelung B, Student J, Nicholls S, Lamers M, Baggio R, Boavida-Portugal I, Johnson P, de Jong E, Hofstede G-J, Pons M, Steiger R, Balbi S (2016) The value of agent-based modelling for assessing tourism-environment interactions in the Anthropocene. Curr Opin Environ Sustainability 23:46-53

Aubke F (2014) Applying a network-lens to hospitality business research: a new research Agenda. Adv Hosp Tour Res 2(2):1-23 
Baggio R (2017) Network science and tourism - the state of the art. Tour Rev 72(1):120-131

Baggio R, Del Chiappa G (2016) Complex tourism systems: a quantitative approach. In: Uysal M, Schwartz Z, Sirakaya-Turk E (eds) Management science in hospitality and tourism: theory, practice and applications. Apple Academic Press, CRC Press, Boca Raton, FL, pp 21-42

Bailer-Jones DM (2002) Models, metaphors and analogies. In: Machamer P, Silberstein M (eds) The Blackwell guide to the philosophy of science, pp 108-127

Barabási AL (2016) Network science. Cambridge University Press, Cambridge

Barabási A-L, Albert R (1999) Emergence of scaling in random networks. Science 286:509-512

Bokulich A (2015) Maxwell, Helmholtz, and the unreasonable effectiveness of the method of physical analogy. Stud Hist Philos Sci 50:28-37

Bornholdt S, Schuster HG (eds) (2003) Handbook of graphs and networks-from genome to the internet. Wiley-VCH, Berlin

Casanueva C, Gallego Á, García-Sánchez MR (2016) Social network analysis in tourism. Curr Issues Tour 19(12):1190-1209

da Fontoura Costa L, Rodrigues A, Travieso G, Villas Boas PR (2007) Characterization of complex networks: a survey of measurements. Adv Phys 56(1):167-242

Diestel R (2016) Graph Theory (5th ed). New York: Springer. http://diestel-graph-theory.com/. Accessed Dec 2016

Faloutsos M, Faloutsos P, Faloutsos C (1999) On power-law relationships of the Internet topology. Comput Commun Rev 29:251-262

Freeman LC (2004) The development of social network analysis: a study in the sociology of science. Vancouver Empirical Press, Vancouver

Johnson P, Nicholls S, Student J, Amelung B, Baggio R, Balbi S, Boavida-Portugal I, de Jong E, Hofstede G-J, Lamers M, Pons M, Steiger R (2017) Easing the adoption of agent-based modelling (ABM) in tourism research. Curr Issues Tour 20(8):801-808

Jørgensen MT (2016) Synergistic social network analysis: a synergistic approach to qualitative and quantitative network analysis. Tour Anal 21(6):559-576

Kelman I, Luthe T, Wyss R, Tørnblad SH, Evers Y, Curran MM, Williams RJ, Berlow EL (2016) Social network analysis and qualitative interviews for assessing geographic characteristics of tourism business networks. PLoS One 11(6):art.e0156028

Marchiori M, Possamai L (2015) Micro-macro analysis of complex networks. PLoS One 10(1):art. e0116670

Mariani M, Baggio R, Fuchs M, Höpken W (2018) Business intelligence and big data in hospitality and tourism-a systematic literature review. Int J Contemp Hospitality Manag 30:10 (in print)

Maromodoro A, Yates D (2016) The metaphysics of relations. Oxford University Press, Oxford

Newman MEJ (2010) Networks - an introduction. Oxford University Press, Oxford

van der Zee E, Vanneste D (2015) Tourism networks unravelled; a review of the literature on networks in tourism management studies. Tour Manag Perspect 15:46-56

Watts DJ, Strogatz SH (1998) Collective dynamics of 'small world' networks. Nature 393(6684):440-442

Wellman B (2002) Structural analysis: from metaphor to theory and substance. In: Scott J (ed) Social networks: critical concepts in sociology, vol 1. Routledge, London, pp 81-122 